\title{
CHROMOSOMAL LOCATION OF A GENE THAT CONTROLS STEROL ESTERIFICATION IN TRITICUM AESTIVUM L.
}

\author{
J.V. TORRES and F. GARCIA-OLMEDO
}

Department of Biochemistry, Politechnical University of Madrid, E.T.S. Ingenieros Agrónomos, Modrid 3 (Spain)

\section{SUMMARY}

A previously described $\mathrm{D}$ genome locus $(P \ln )$ that controls sterol esterification in the wheat kernel has been assigned to the short arm of chromosome $7 \mathrm{D}$ by comparison of the steryl ester phenotype of euploid kernels of Triticum aestivum variety Chinese Spring with those of the compensated nulli-tetrasomic lines and the $7 \mathrm{D} \mathrm{S}$ ditelosomic. Palmitate is the predominant ester in all but the $7 \mathrm{D}$ nullisomic combinations, which have linoleate as the main ester. These lines also show a marked decrease in sterol esterification and a two-fold increase in free sterol, indicating that chromosomes $7 \mathrm{~A}$ and $7 \mathrm{~B}$ do not compensate for the loss of esterification capacity associated with 7 D.

\section{INTRODUCTION}

It is widely acknowledged that the physiological functions of higher plant sterols have nowhere near been established [1-9]. Free sterols, steryl esters, steryl glycosides and acylated steryl glycosides have been isolated from different tissues in a number of plant species. These sterol forms have been analyzed during development and differentiation processes, such as seed development and germination, senescence, etc., in order to find some clues to their functions. Although such investigations have been largely inconclusive in this connection, they have at least resulted in the formulation of some hypotheses concerning the physiological roles of these compounds.

It has been postulated that free sterols are integral parts of plant cell membranes, where they influence cell permeability $[3,4]$. However, only cholesterol and campesterol have been shown to change permeability of excised barley roots, while the major higher plant sterols, $\beta$-sitosterol and stigmasterol, were virtually ineffective [4].

Abbreviations: L, linoleate (pattern); PL, palmitate (pattern). 
Cholesterol and $\beta$-sitosterol can act as precursors of C-21 plant steroids, but this function can hardly justify the high level of free sterol in most plant tissues [2].

Steryl esters have been variously implicated in storage [5], transport $[1,3-5]$ and subtraction of free sterols from membranes in senescent cotyledons [5].

Finally the glycosides, acylated and non-acylated, have been considered as reserved forms [7], or as structural elements [8], based on their evolution during germination.

Experimental data obtained by different workers for different species are somewhat conflicting and do not make it possible to draw a general picture of some fundamental matters, such as intracellular distribution of sterol forms, their evolution in reserve and developing tissues, etc.

In our opinion, some of the above hypotheses could be tested and some of the discrepancies resolved if intra-specific genetic variants affecting sterol metabolism could be compared in near-isogenic backgrounds and correlated with intra-specific physiological differences. Compensated nulli-tetrasomic lines of hexaploid wheat obtained by E.R. Sears can be suitable for such studies, provided that homoeologous loci affecting a given function do not produce very similar effects. This is the case of a previously described [10-12] D genome locus $(P l n)$ that controls steryl ester pattern. We report here our investigation of nulli-tetrasomic lines of Triticum aestivum, variety Chinese Spring, in order to locate this gene and to search for other possible noncompensated homoeologous loci affecting sterol metabolism..

\section{MATERIAL AND METHODS}

Nulli-tetrasomic lines of wheat, variety Chinese Spring, (T. aestivum L.) were obtained from E.R. Sears and from T. Mello-Sampayo, who also provided the $7 \mathrm{DS}$ ditelosomic.

Two kernels from each line were cut in in half with a razor blade. The halves distal from the embryo were used for biochemical analysis and those including the embryo for cytological control and multiplication.

The half kernels were squashed between two polished metal plates and transferred to small tubes. Extraction was performed with diethyl ether $(5+5 \mathrm{vol}$ ), first for $16 \mathrm{~h}$, with four 1-min periods of sonication in a cleaning bath (Varian $A G$ ), then for $30 \mathrm{~min}$, with $1 \mathrm{~min}$ sonication. It was previously found that extraction with chloroform:methanol $(2: 1)$ or water-saturated $n$-butanol did not increase the yield of free and sterified sterol.

The extracts were directly spotted under nitrogen in a Silicagel plate ( $0.2 \mathrm{~mm}$ thick) with the aid of a capillary tube. Two $18-\mathrm{cm}$ runs with carbon tetrachloride and a $10-\mathrm{cm}$ run with benzene : ethyl acetate (95:18) [13] resolved the individual esters and the free sterol in a single plate. Authentic samples of cholesteryl palmitate (Serva), oleate and linoleate (Merck AG) and $\beta$-sitosterol (Serva) were also run in the TLC. 
Quantitation of the different sterol fractions was performed by a modification of the fluorometric method of Bondjers and Bjorkerud [14]: Following chromatography, the plates were exposed to iodine vapor and the sterol spots were marked. After disappearance of iodine from the spots, these were scraped and twice extracted with chloroform. The combined extracts were brought up to $3.5 \mathrm{ml}$, then $0.25 \mathrm{ml}$ of $\mathrm{ZnCl}_{2}$ reagent and $0.25 \mathrm{ml}$ of acetyl chloride were added. After $40 \mathrm{~min}$ at $60^{\circ}$ in a thermoblock, the tubes were cooled and the fluorescence measured in a Turner fluorometer (filters $7-60$, $365 \mathrm{~m} \mu$, and $2 \mathrm{~A}, 415 \mathrm{~m} \mu$ ). Two sets of standards were used: one was run through the complete procedure and the other was directly subjected to fluorometry. Recovery was higher than $95 \%$.

\section{RESULTS AND DISCUSSION}

Two steryl ester patterns, designated PL and L after their main esters, have been found in mature kernels from species of the Aegilops - Triticum group [12] and from other Gramineae (Agropyron, Secale [10], Zea, Hordeum, Avena [15]). The PL pattern is more widely distributed than the $L$ in diploid species and shows dominance over it in synthetic and natural alloploids in which L and PL genomes coexist [12]. All tetraploid wheats included in our studies ( $T$. durum, $T$. turgidum and $T$. polonicum, genomes AB, and $T$. timopheevi, $\mathrm{AB}$ ) show the $\mathrm{L}$ pattern, while most $T$. aestivum (ABD) varieties and all D genome species (Ae. squarrosa, D, Ae. crassa, DMcr, Ae. ventricosa, $\mathrm{DM}^{v}, A e$. cylindrica, $\mathrm{DC}$, and Ae. juvenalis, $\mathrm{DC} \mathrm{M}$ ) have the $\mathrm{PL}$ phenotype. Appropriate crosses between $\mathrm{PL}$ and $\mathrm{L}$ varieties indicated that steryl palmitate is inherited as though determined by a dominant allele at a single locus, designed PIn [12].

Free and sterified sterol patterns of the nulli-tetrasomic lines, the euploid and the $7 \mathrm{D} \mathrm{S}$ ditelosomic are shown in Fig. 1. Both nulli-7 D combinations show the $\mathrm{L}$ phenotype, while the euploid, the $7 \mathrm{D} \mathrm{S}$ ditelosomic and the remaining nulli-tetrasomics show the PL pattern. No other drastic change in the steryl esters of the nulli-tetrasomics is observed. We therefore conclude that gene Pln is located in the short arm of chromosome $7 \mathrm{D}$.

An increased proportion of free sterol is associated with the decrease in steryl palmitate presented by lines nulli $7 \mathrm{D}$ - tetra $7 \mathrm{~A}$ and $7 \mathrm{D}$ - tetra $7 \mathrm{~B}$. This is more clearly shown in Table I, where data for homoeologous chromosome group 7 are expressed on a dry matter basis. A reduction of $80-90 \%$ in steryl palmitate net synthesis and a more than $100 \%$ increment in free sterol indicate that chromosomes $7 \mathrm{~A}$ and $7 \mathrm{~B}$ do not compensate for the loss of esterifying capacity associated with chromosome $7 \mathrm{D}$. On the other hand, tetra $7 \mathrm{D}$ lines do not show an increase in steryl palmitate or in total esters, which is consistent with our previous observation of no dose effect for allele $P \ln [12]$.

All diploid species, including Ae. squarrosa (D) and Ae. speltoides (potential B genome donor) also synthesize steryl linoleate. This observation 


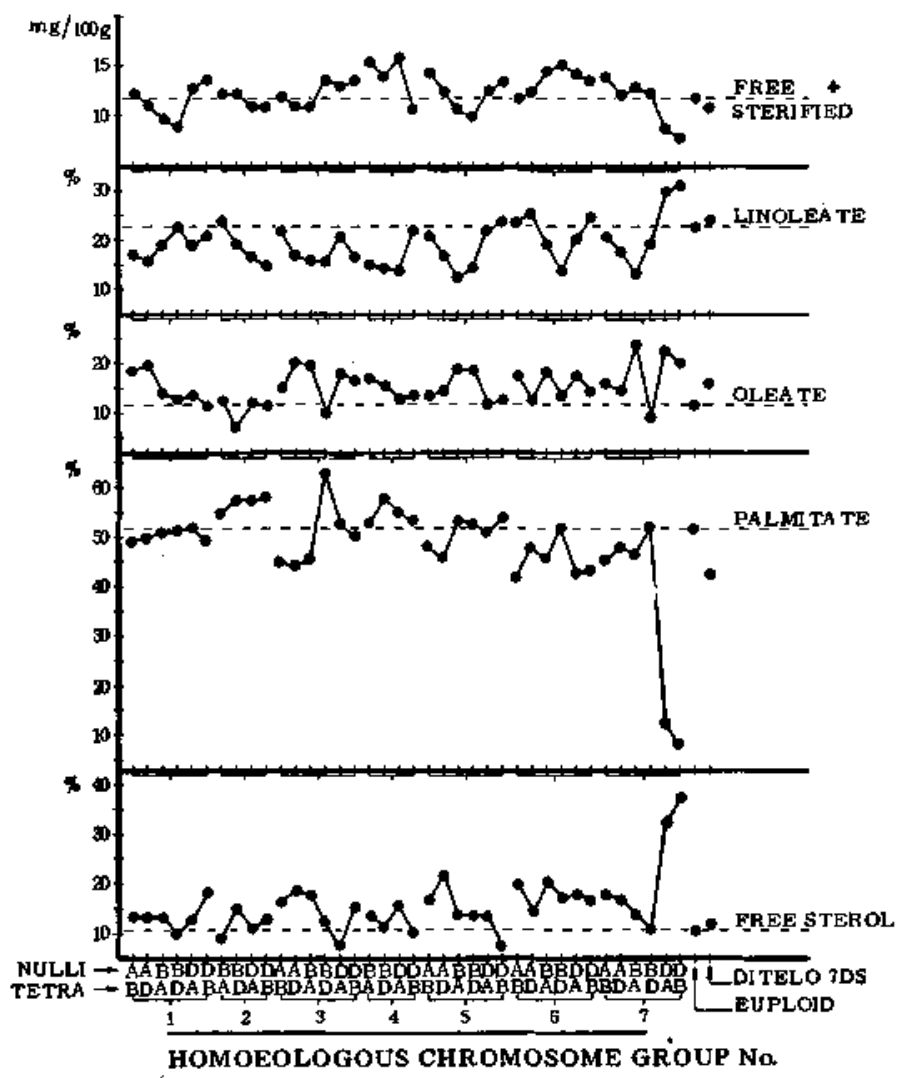

Fig.1. Free and esterified sterol patterns in compensated nulli-tetrasomic, euploid, and $7 \mathrm{D} \mathrm{S}$ ditelosomic lines of $T$. aestivum var. Chinese Spring. Free plus esterified sterol is expressed in $\mathrm{mg} / 100 \mathrm{~g}$ dry matter. Sterol in each fraction is expressed as \% of free plus esterified.

\section{TABLE I}

FREE AND ESTERIFIED STEROL IN COMPENSATED NULLI-TETRASOMICS OF GROUP 7

\begin{tabular}{|c|c|c|c|c|c|c|}
\hline \multicolumn{2}{|l|}{ Line } & \multicolumn{5}{|c|}{$\mathrm{mg}$ sterol $/ 100 \mathrm{~g}$ dry matter } \\
\hline Nulli & Tetra & Free & Palmitate & Oleate & Linoleate & Free + esterified \\
\hline $\begin{array}{l}7 \mathrm{~A} \\
7 \mathrm{~A} \\
7 \mathrm{~B} \\
7 \mathrm{~B} \\
7 \mathrm{D} \\
7 \mathrm{D} \\
\text { Euploid }\end{array}$ & 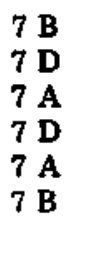 & $\begin{array}{l}2.7 \\
2.2 \\
2.0 \\
2.3 \\
3.0 \\
3.0 \\
1.4\end{array}$ & $\begin{array}{l}6.5 \\
5.8 \\
6.1 \\
6.8 \\
1.2 \\
0.7 \\
6.3\end{array}$ & $\begin{array}{l}2.2 \\
2.0 \\
3.2 \\
1.3 \\
2.2 \\
1.7 \\
1.5\end{array}$ & $\begin{array}{l}3.1 \\
2.3 \\
1.8 \\
2.4 \\
2.8 \\
2.4 \\
2.8\end{array}$ & $\begin{array}{r}14.5 \\
12.3 \\
13.1 \\
12.8 \\
9.2 \\
7.8 \\
12.0\end{array}$ \\
\hline
\end{tabular}


and the fact that enzymes involved in steryl ester synthesis and degradation, characterized in other biological systems, are not specific for a single fatty acid, led us to the following tentative conclusions: ( $i$ ) gene Pln is responsible for palmitate and linoleate synthesis and the $\mathrm{L}$ pattern is controlled by an alternative variant of gene Pln; (ii) if the B genome donor was a PL diploid, steryl ester synthetic capacity associated to the B genome was lost early in tetraploid wheat evolution, and (iii) part of the synthetic capacity for linoleate in $T$. aestivum (ABD) is associated with the D genome $[12,16]$. Since no significant changes of linoleate level are associated with any group 7 chromosome, the above conclusions cannot be corroborated or discarded. The results in Table I are compatible with full compensation for linoleate synthesis between chromosomes of group 7, with lack of dose effect, or even with control of this synthesis by genes located in a different homoeologous group.

Present availability of nulli-tetrasomics did not permit us to investigate their steryl glycosides or the anatomical and subcellular distribution of their free and sterified sterol. The above results have led us to a re-investigation of the action of gene Pln during kernel development to be published elsewhere. Ten-fold intraspecific differences in endosperm free sterol have been found and their correlation with physiological differences is being investigated.

\section{ACKNOWLEDGEMENTS}

We thank Drs. E.R. Sears and T. Mello-Sampayo for the gift of samples.

\section{REFERENCES}

1 R.J. Kemp, L.J. Goad and E.J. Mercer, Phytochemistry, 6 (1967) 1609.

2 R.D. Bennett, E. Heftmann and B.J. Winter, Phy tochemistry, 8 (1969) 2325.

3 C. Grunwald, Plant Physiol., 45 (1970) 663.

4 C. Grunwald, Plant Physiol., 48 (1971) 653.

5 Paulette Dupéron, Physiol. Vég., 9 (1971) 373.

6 R. Dupéron, Michele Brillard and Paulette Dupéron, Compt. Rend., 274 (1972) 2321.

7 P.B. Bush and C. Grunwald, Plant Physiol., 50 (1972) 69.

8 Joëlle Méance and R. Dupéron, Compt. Rend., 277 (1973) 849.

9 Marie-Andrée Hartman, Mina Ferne, C. Gigot, R. Brandt and P. Benveniste, Physiol. Vég., 11 (1973) 209.

10 F. García-Olmedo, Bol. Inst. Nac. Invest. Agron., 25 (1965) 409.

11 R. García-Faure, F. García-Olmedo and M. Vallejo, J. Sci. Fd Agric., 19 (1968) 322.

12 F. García-Olmedo, Nature, 220 (1968) 1144.

13 S.K. Skarsaune, V.L. Youngs and K.A. Gilles, Cereal Chem., 47 (1970) 533.

14 G. Bondjers and Björkerud Anal. Biochem., 42 (1971) 363.

15 K.A. Gilles and V.L. Youngs, Cereal Chem., 41 (1964) 502.

16 P. Carbonero and F. García-Olmedo, Experientia, 25 (1969) 1110. 